\title{
Experimental Investigation on the Thermal Behavior of Untreated and Alkali-Treated Pineapple Leaf and Coconut Husk Fibers
}

\author{
Mohit Mittal* and Rajiv Chaudhary² \\ Department of Mechanical, Production and Industrial Engineering, Delhi Technological University, Delhi-110042, India \\ *Corresponding author: mohit.30mittal@gmail.com
}

\begin{abstract}
The primary objective of this research work is to study the thermal behavior of untreated and alkali treated pineapple leaf (PALF) and coconut husk fibers (COIR). In this context, firstly the cellulosic fibers were treated with an alkali solution of various concentration $(2 \%, 4 \%, 6 \%, 8 \%$, and $10 \mathrm{wt} \%)$ then secondly the change in their surface chemistry and thermal stability were investigated by means of a Fourier transform infrared spectroscopy (FTIR) and Thermogravimetric analysis technique (TGA) respectively. A significant variation in the chemical composition of cellulosic fibers was observed after an alkaline treatment. Changes in the peak at 1745,1525 , and $1250 \mathrm{~cm}^{-1}$ in FTIR spectra corresponds to the partial removal of hemicellulose and lignin components. The thermal degradation of lignocellulosic fibers consists of two major steps i.e. moisture loss (below $150^{\circ} \mathrm{C}$ ) and the decomposition of hemicellulose, cellulose, and lignin components (between $150^{\circ} \mathrm{C}$ to $400^{\circ} \mathrm{C}$ ). An alkali treatment increases the thermal stability of pineapple leaf and coir fibers through physical and chemical changes. It was observed that the $4 \mathrm{wt} \% \mathrm{NaOH}$ treated PALF and COIR fibers possess higher thermal stability as compared to other treated and untreated fibers. PALF exhibits a higher rate of decomposition than the COIR fiber but its main decomposition peak lies at a higher temperature of about $40^{\circ} \mathrm{C}$.
\end{abstract}

Keywords: Pineapple leaf fiber, Coir fiber, Alkali treatment (NaOH), Thermal stability, Thermogravimetric analysis (TGA), Natural fiber, Infrared spectroscopy

Recently, most of the industries are looking for those materials which have environment-friendly characteristics, contribute to the lower emission of pollutants, good physical properties, and economical in nature ${ }^{[1-3]}$. To fulfill the market demands, researchers and technologists are putting their attention towards biocomposite materials. These materials generally made up of lignocellulosic biomass and polymeric resin. 
Amongst all the different types of lignocellulosic materials, the coconut husk (COIR) and pineapple leaf fibers (PALF) have high potential to develop high strength biocomposite materials since they possess a large number of advantageous properties such as low cost, lightweight, easy processing, easy availability, high specific strength and stiffness, and non-abrasive nature ${ }^{[4-5]}$. The COIR and PALF can obtain from the husk of coconut fruit (Cocos nucifera) and leaves of pineapple fruit (Ananas-comosus) respectively. The inherent properties of COIR and PALF are mentioned in Table $1^{[6]}$. COIR fiber contains more amount of lignin as compared to other typically used natural fibers which result it has good resistance to salt water, microbial, and fungus attack. In comparison to COIR, the PALF is a smooth, flexible, thin, and long fiber. PALF can be employed as an electrical, thermal, and acoustic insulator; for feedstock, and biofuel production $^{[7-10]}$. According to the statistical database (2016) of "Food and Agriculture Organization," the total production of coconut and pineapple fruit in the whole world is 59 and 25.8 millions of tonnes respectively (Table 2) ${ }^{[11]}$. Inspite of the above mentioned profitable properties, they exhibit some limitations like hydrophilicity, poor wettability, low thermal stability, and poor interfacial adhesion with synthetic polymers which results that all the capabilities of developed biomaterials cannot be exploited to full extent. In this regard, researchers have done a lot of work to impart hydrophobicity in natural fibers by chemical treatment process such as maleic anhydride, peroxide, permanganate, sodium hydroxide, and organosilanes etc. But very little work has been done to improve the thermal stability of lignocellulosic fibers ${ }^{[12-15]}$. Previous work ${ }^{[16-18]}$ has reported that the natural fibers can be subjected to thermal degradation during the biocomposite processing. So, it is practically significant to understand and overcome the thermal decomposition of natural polymeric materials. Their thermal behavior mainly depends on the chemical composition and internal structure. The constituents of natural fibers such as hemicellulose, cellulose, lignin, pectin, and waxes are not thermally stable even at a relatively low temperature (below $400^{\circ} \mathrm{C}$ ). The initial decomposition of natural fibers starts at around $200^{\circ} \mathrm{C}$ and it was due to the cellular breakdown of hemicellulose. The previous research work ${ }^{[19-21]}$ concluded that the major decomposition of rice husk, natural hemp, and bagasse fibers occur at $351.5^{\circ} \mathrm{C}, 312^{\circ} \mathrm{C}$, and $327^{\circ} \mathrm{C}$ respectively due to the decomposition of $\alpha$-cellulose.

Thermogravimetric analysis (TGA) is one of the most popular and widely used techniques to analyze the decomposition process of solid material, kinetic analysis of de-volatilization, and to study the effects of heating rate, temperature, pressure, atmosphere gas, gas flow rate, biomass composition, and particles size on mass loss of a sample ${ }^{[22]}$. Yao Fei et al. ${ }^{[23]}$ have studied the decomposition kinetics of 10 types of fibers and found that the activation energy of Bagasse, Bamboo, Cotton Silk, Hemp, Jute, Kenaf, Rice husk, Rice straw, Wood maple, and Wood pine were 161.1, 161,6, 146, 171.1, 165.6, 157.7, 167.4, 176.2, 153.7, 159.3 respectively. The thermal decomposition of natural fibers consists of two to three steps based on their type and chemical composition. Sergio et al. ${ }^{[24]}$ stated that the thermal decomposition of NFRC consists of moisture evaporation, hemicellulose degradation, and decomposition of $\alpha$-cellulose, and lignin. A. Rachini et al. ${ }^{[25]}$ reported the order of thermal stability of hemp fiber: $\mathrm{NaOH}$ treated fibers $>$ silane-treated fibers $>$ solvent extracted fibers (water/ethanol mixture, 20/80 v/v) $>$ untreated hemp fibers. M. Tajvidi et al. ${ }^{[26]}$ studied the thermal degradation of wood flour, kenaf fiber, newsprint, and rice hulls - polypropylene composites. $\mathrm{Na} \mathrm{Lu}$ et al. ${ }^{[27]}$ reported that the hemp fiber was decomposed in two steps, starting with the loss of moisture around $100^{\circ} \mathrm{C}$ and followed by successive decomposition of hemicellulose, cellulose, and lignin in the range of $150-400^{\circ} \mathrm{C}$. Jayamani Elammaran et al ${ }^{[28]}$ reported that the thermal decomposition of Betel nut-Polyester composite was shifted to a higher temperature after an alkaline treatment of betel fibers. Alkaline treatment is one of the commonly used cost-effective 
techniques to develop high-performance biocomposite material. The previous research work reported in Table 3 also assured the researchers about the positive attributes of an alkaline treatment. However, very little work has been done towards the effect of alkaline treatment on thermal stability of natural fibers. Therefore, in the present communication, an experimental investigation has been carried out to study the effect of alkaline treatment of various concentrations $(2 \%, 4 \%, 6 \%, 8 \%$ and $10 \%)$ on the thermal behavior of pineapple leaf and coir fibers. FTIR spectroscopy was also used to characterize the surface chemistry of untreated and alkali treated $(\mathrm{NaOH})$ fibers. The thermo-chemical decomposition reaction of untreated and $\mathrm{NaOH}$ treated cellulosic fibers were studied by employing a TGA instrument.

Table 1: Physical properties of pineapple leaf and coir fiber ${ }^{[6]}$

\begin{tabular}{ccc}
\hline Physical properties & Pineapple leaf fiber & Coir fiber \\
\hline Density $\left(\mathrm{g} / \mathrm{cm}^{3}\right)$ & 0.98 & 1.2 \\
Cellulose $(\%)$ & $70-82$ & $32-43$ \\
Hemicellulose (\%) & 18.8 & $0.15-0.25$ \\
Lignin (\%) & $5-12.7$ & $40-45$ \\
Pectin (\%) & 1.1 & $3-4$ \\
Moisture content (\%) & 11.8 & 8 \\
Microfibrillar angle (deg) & 14 & $30-49$ \\
Diameter $(\mu \mathrm{m})$ & $20-80$ & $100-460$ \\
Tensile strength $(\mathrm{MPa})$ & $413-1627$ & $131-220$ \\
Young's modulus $(\mathrm{GPa})$ & $34.5-82.5$ & $4-6$ \\
Elongation at break $(\%)$ & 1.6 & $15-40$ \\
\hline
\end{tabular}

Table 2: Total annual production of pineapple leaf and coir fiber

\begin{tabular}{cccc}
\hline \multicolumn{2}{c}{ Pineapple Production-2016 } & \multicolumn{2}{c}{ Coconut Production-2016 } \\
\hline Country & Millions of tonnes & Country & Millions of tonnes \\
\hline Costa Rica & 2.9 & Indonesia & 17.7 \\
Brazil & 2.7 & Philippines & 13.8 \\
Philippines & 2.6 & India & 11.1 \\
Thailand & 1.9 & Brazil & 2.6 \\
India & 1.9 & Sri Lanka & 2.5 \\
Indonesia & 1.3 & & \\
World & 25.8 & World & 59.0 \\
\hline
\end{tabular}

Table 3: Previous research work reported on the alkaline treatment of cellulosic fibers

\begin{tabular}{|c|c|c|}
\hline Authors & $\begin{array}{l}\text { Factors explored by } \\
\text { researchers }\end{array}$ & Results \\
\hline $\begin{array}{l}\text { M. Mittal et al. } \\
\text { (2018) }\end{array}$ & $\begin{array}{l}\text { Effect of alkaline treatment on } \\
\text { the mechanical properties of } \\
\text { PALF/Glass hybrid composite. }\end{array}$ & $\begin{array}{l}\text { The } 15 / 15(\mathrm{v} / \mathrm{v}) \text { alkaline treated PALF/Glass composite [29] } \\
\text { exhibits } 35 \% \text { higher flexural strength than that of the } \\
\text { pure Glass-Epoxy composite. }\end{array}$ \\
\hline $\begin{array}{l}\text { R. Ranjan et al. } \\
(2013)\end{array}$ & $\begin{array}{l}\text { Effect of alkali treatment on } \\
\text { the mechanical properties of } \\
\text { Banana/Sisal fiber reinforced } \\
\text { PLA composites. }\end{array}$ & $\begin{array}{l}\text { The } 2 \mathrm{wt} \% \mathrm{NaOH} \text { treated composite has better } \\
\text { mechanical properties (tensile, flexural, and impact } \\
\text { strength) than the untreated composites. }\end{array}$ \\
\hline
\end{tabular}


L. Uma Devi et al. (2011)

Effect of chemical treatment on the water absorption behavior of PALF/GF fiber reinforced polyester composites.

G. Goud et al. (2010)

Effect of alkali treatment on the mechanical properties of Roystonea regia fiber reinforced epoxy composites

P. Anand et al. (2014)

Effect of alkali treatment on the mechanical properties of hemp fiber reinforced epoxy composite

S.C Effect of alkali treatment on Venkateshappa et the mechanical properties of al. (2011) areca fiber reinforced epoxy composites
The alkali treated composites possess higher res
to water sorption than the untreated composites.

Alkali-treated fiber reinforced composite showed better tensile and flexural properties than that of the untreated composite.

Alkali-treated hemp fiber composite yields better mechanical properties than that of untreated composites.

The tensile, flexural, and compressive strength of composites were increased after the alkali treatment of areca fiber.

\section{EXPERIMENTAL DETAILS}

\section{Materials}

Two different types of lignocellulosic fiber were used in this study, viz., coconut husk (Coco Nucifera) and pineapple leaf fiber (Ananas comosus). These cellulosic fibers were obtained from M/s Go Green Products, Chennai (India). Table 1 shows the chemical composition of PALF and COIR fibers ${ }^{[6]}$. Sodium hydroxide $(\mathrm{NaOH})$ used for an alkaline treatment was of laboratory reagent (LR) grade and obtained from a local supplier.

\section{Fiber treatment}

PALF and COIR fibers were soaked in various concentrations $(2 \%, 4 \%, 6 \%, 8 \%$ and $10 \mathrm{wt} \%)$ of alkaline solution for $24 \mathrm{hr}$ at room temperature, followed by washing with deionized water and drying in an oven at $60^{\circ} \mathrm{C}$ for $24 \mathrm{hr}$. The untreated cellulosic fibers were also washed and dried to remove the surface impurities and absorbed water molecules.

\section{Fourier-Transform Infrared Spectroscopy (FTIR)}

Fourier-transform infrared spectroscopy (Perkin Elmer 2000) was used to analyze the surface chemistry of untreated and alkali treated PALF and COIR fibers. FTIR spectroscopy of the cellulosic fibers had done in Analytical Instrumentation Laboratory, CSIR-CSIO, Chandigarh (India).

\section{Thermogravimetric Analysis (TGA)}

Thermal analysis of COIR and PALF (untreated and alkali treated) was carried out by using a thermogravimetric analyzer (Perkin Elmer, TGA 4000). A sample of mass $5 \mathrm{mg}$ was evenly and uniformly 
distributed in the alumina crucible which was supported by a precision balance. This small amount of fiber was taken for uniformity of temperature throughout the sample. The variation in mass of a sample with respect to temperature and time was monitored and recorded by Perkin Elmer thermal software (Pyris). The temperature was ranged from $25^{\circ} \mathrm{C}$ to $700^{\circ} \mathrm{C}$ with a heating rate of $10^{\circ} \mathrm{C} / \mathrm{min}$ under the high purity nitrogen (inert) atmosphere at a flow rate of $20 \mathrm{ml} / \mathrm{min}$. The heating rate of $10^{\circ} \mathrm{C} / \mathrm{min}$ was selected for better resolution of transition.

\section{RESULTS AND DISCUSSION}

\section{Fourier-Transform Infrared Spectroscopy (FTIR)}

Fig. 1 and 2 illustrates the FTIR spectra of COIR and PALF respectively. It was observed that the surface chemistry of cellulosic fibers was changed after an alkaline treatment. An increase in intensity around 3300 $\mathrm{cm}^{-1}$ and $1000 \mathrm{~cm}^{-1}$ after an alkaline treatment corresponds to the higher accessibility of -OH functional group. This was due to the removal of waxy and gummy substances. The increase in peak intensity at around $1600-1650 \mathrm{~cm}^{-1}$ and $1250 \mathrm{~cm}^{-1}$ after an alkaline treatment also confirmed the removal of wax, adhesives, pectin, and gummy substances from the fiber surface. The absorption peak at $1745 \mathrm{~cm}^{-1}$ was observed in raw fibers (PALF and COIR) but disappears after $\mathrm{NaOH}$ treatment. It is related with $\mathrm{C}=\mathrm{O}$ stretch and confirmed the removal of hemicellulose.

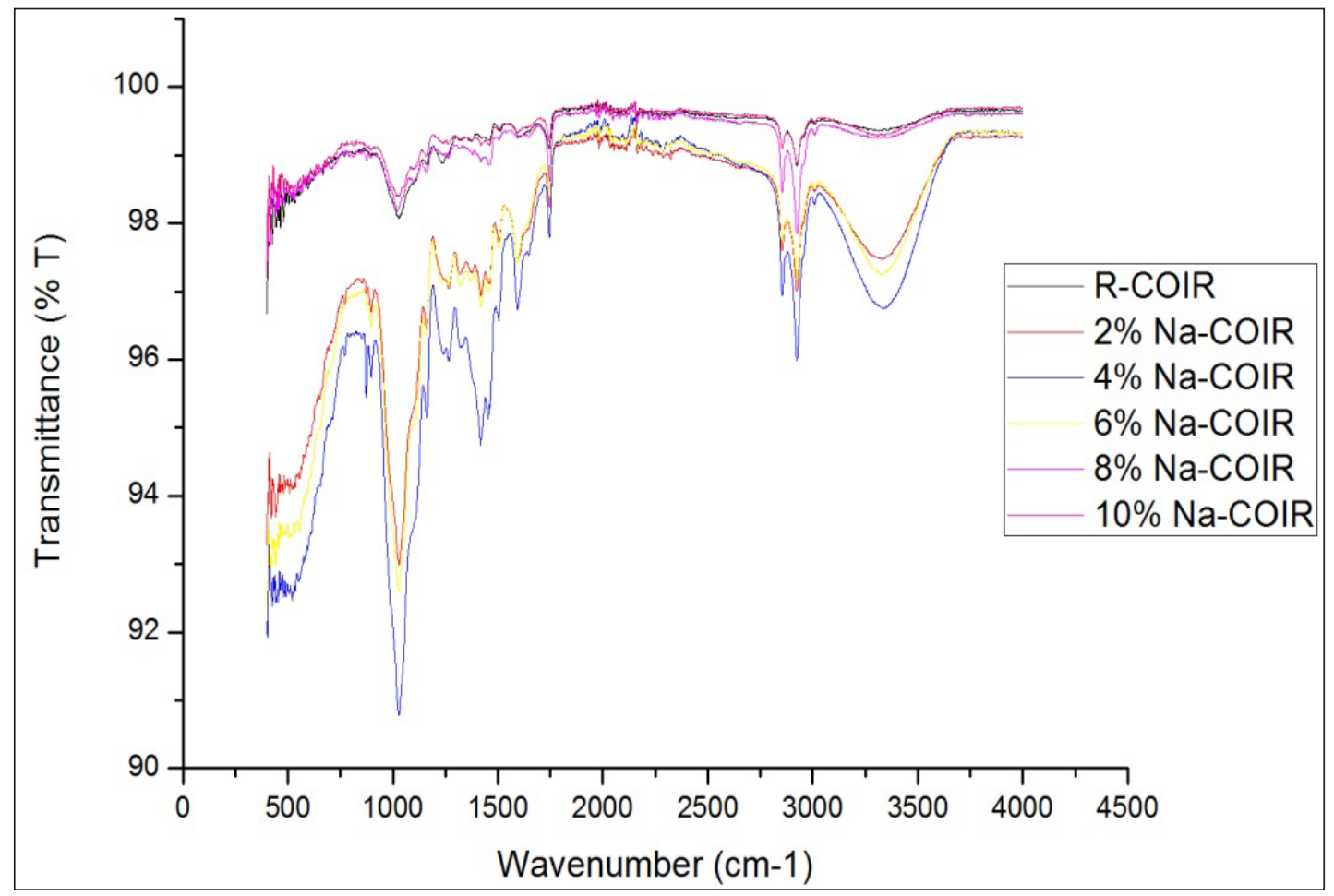

Fig. 1: IR spectra of untreated and alkali treated coir fiber 


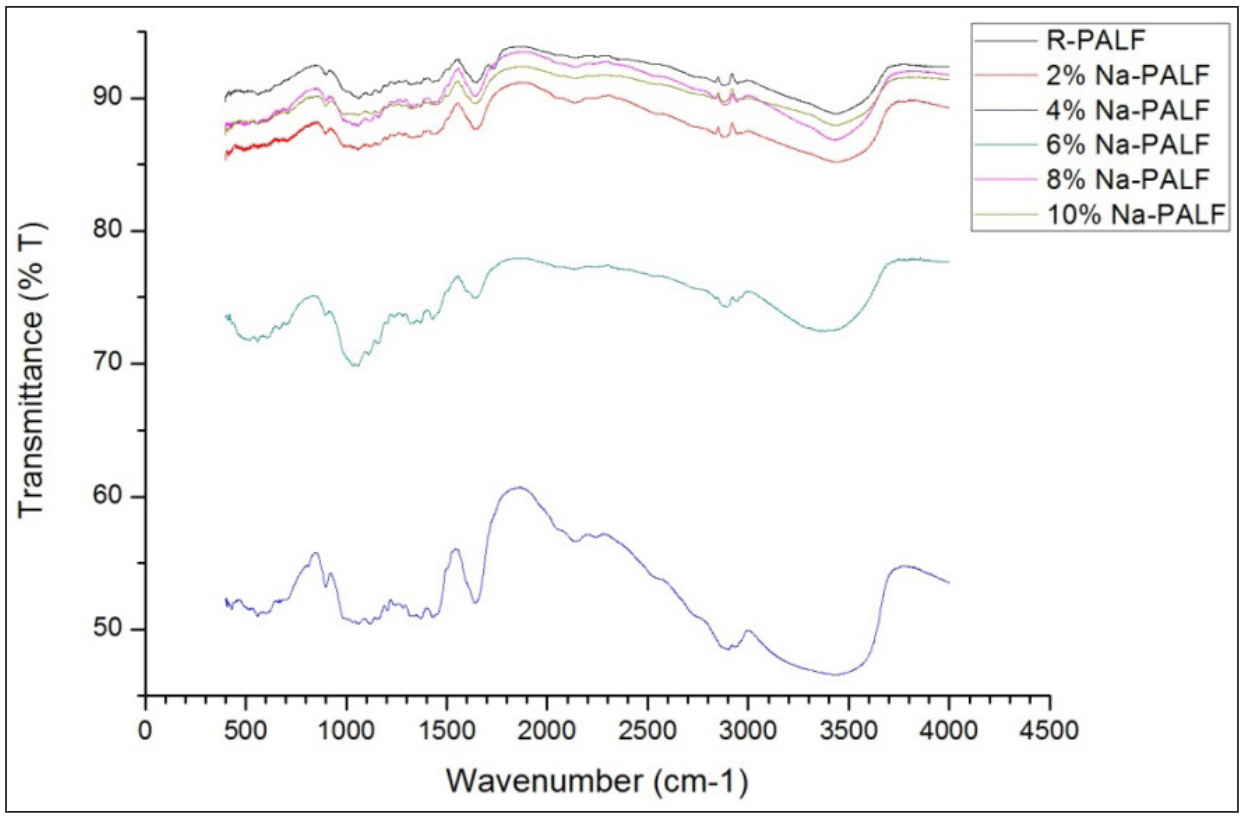

Fig. 2: IR spectra of untreated and alkali treated pineapple leaf fiber

The IR spectra of raw PALF and COIR fibers are shown in Fig. 3. It was observed that the PALF consists a large amount of hydroxyl (-OH) group than that of COIR fiber. The broad peak in the region 3200-3500 $\mathrm{cm}^{-1}$ is attributed to the vibration of $-\mathrm{OH}$ group. The peak at $1244 \mathrm{~cm}^{-1}$ is much smaller in PALF than COIR. This peak corresponds to the $\mathrm{C}=\mathrm{O}$ stretch of an acetyl group of lignin.

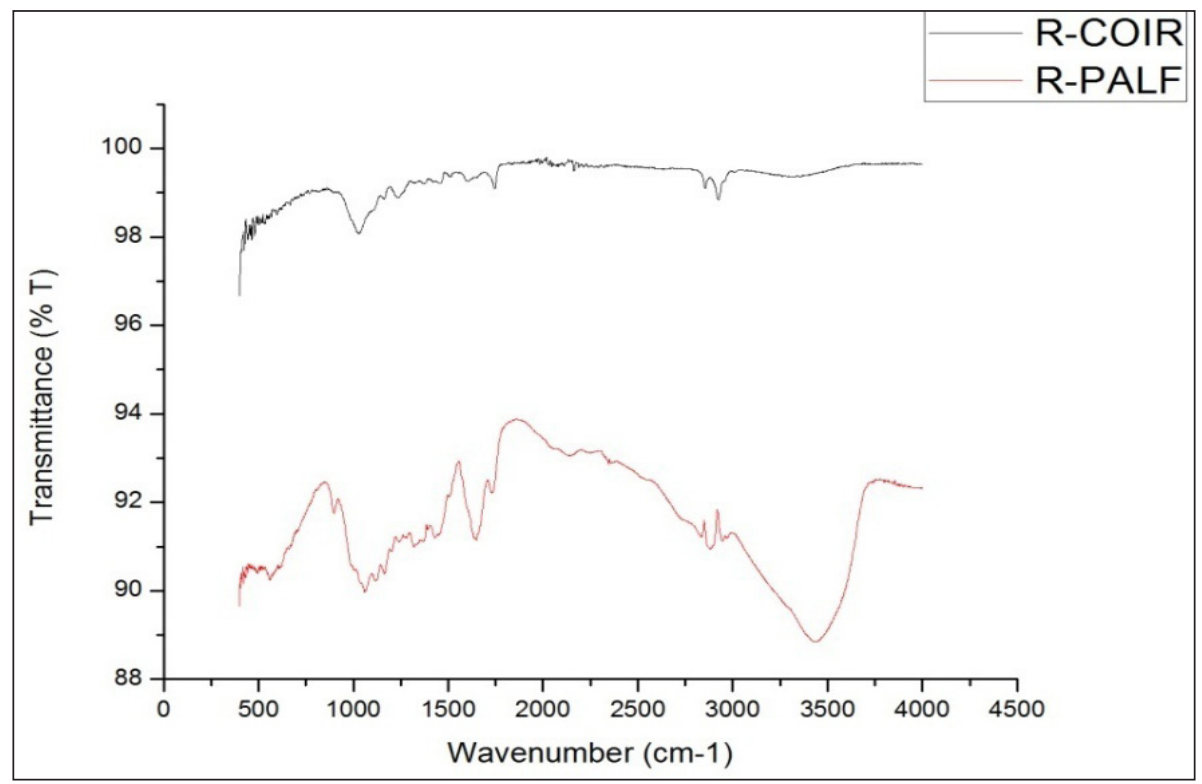

Fig. 3: IR spectra of coir and pineapple leaf fiber 


\section{Thermal Decomposition of Untreated and Alkali-Treated Pineapple Leaf and Coir Fibers}

TGA and DTG curves of untreated and alkali treated $(2 \%, 4 \%, 6 \%, 8 \%$, and $10 \%)$ COIR and PALF fibers are shown in Figs 4-9 and the corresponding weight loss as a function of temperature is mentioned in Table 4 and 5. In all cases, the initial stage of decomposition occurs between $30^{\circ} \mathrm{C}$ to $185^{\circ} \mathrm{C}$ which indicate the release of bound water and volatile extractives. The previous work (Slopiecka et al. ${ }^{[16]}$, Ndazi Bwire et al. ${ }^{[35]}$ ) are also reported that all the types of natural fiber exhibit endothermic decomposition (within 5-10\% range) due to an evaporation of moisture, but the rate of evaporation depends on the hydrophilicity of natural fibers. The peak temperature corresponds to the moisture loss appear at $48^{\circ} \mathrm{C}$ and $31^{\circ} \mathrm{C}$ for untreated COIR and PALF respectively. The PALF exhibits a higher rate of moisture loss than that of COIR fiber. This might be due to the high moisture content in PALF. Table 3 depicts that the $4 \mathrm{wt} \% \mathrm{NaOH}$ treated PALF exhibits less weight loss (around 48\%) due to moisture evaporation as compared to the untreated fiber. This was attributed to the removal of hemicellulose, pectin, and waxy substances after an alkaline treatment. Arifuzzaman Khan et al.$^{[36]}$ also reported that the percentage of initial weight loss due to moisture evaporation is higher in untreated COIR fiber than that of $\mathrm{NaOH}$ treated one. At $100^{\circ} \mathrm{C}, 8 \mathrm{wt} \%$ alkaline treated COIR fibers possess less weight loss (approx. $40 \%$ ) as compared to raw fibers. Ndazi et al. ${ }^{[35]}$ concluded that the structurally bound water is resistant to complete water removal during drying.



Fig. 4: TGA curves of untreated and alkali treated coir fibers 


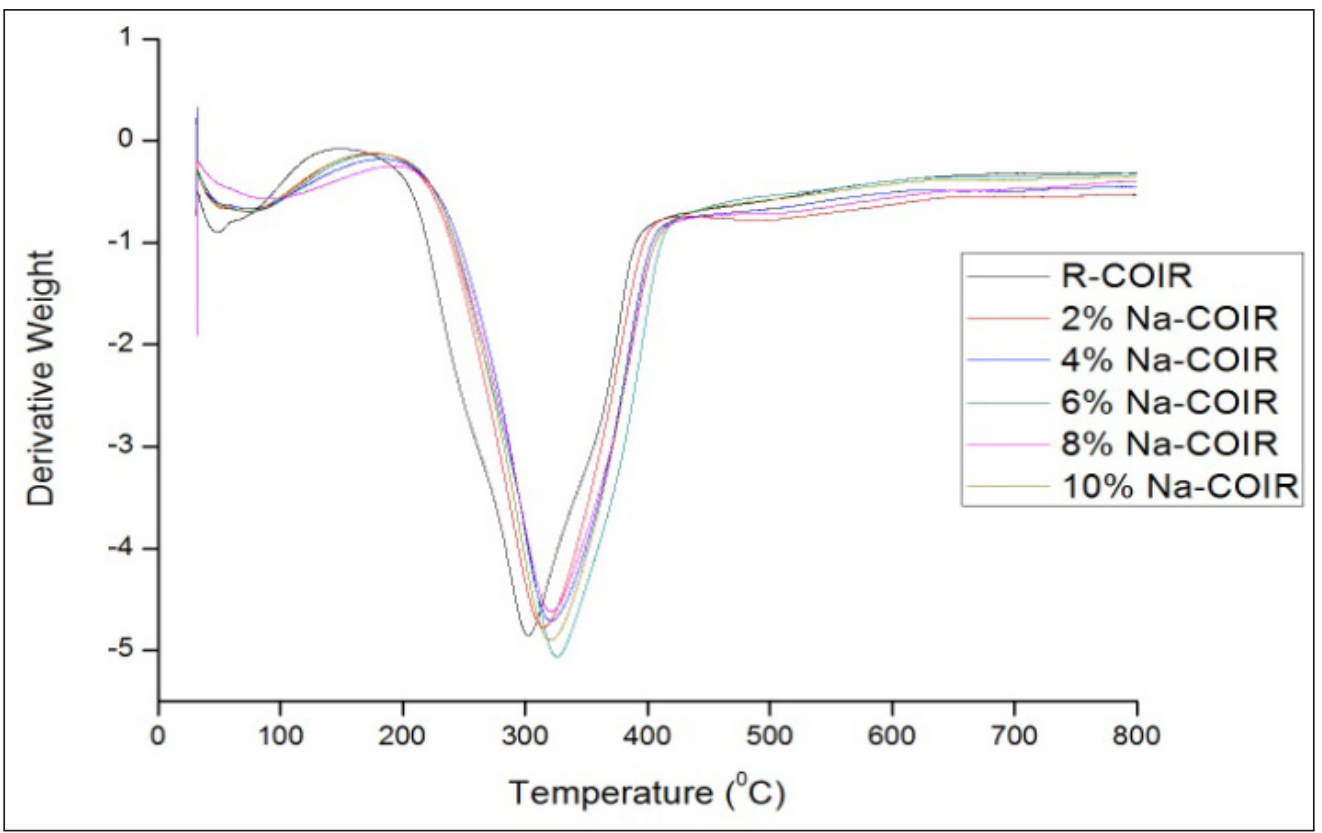

Fig. 5: DTG curves of untreated and alkali treated coir fibers

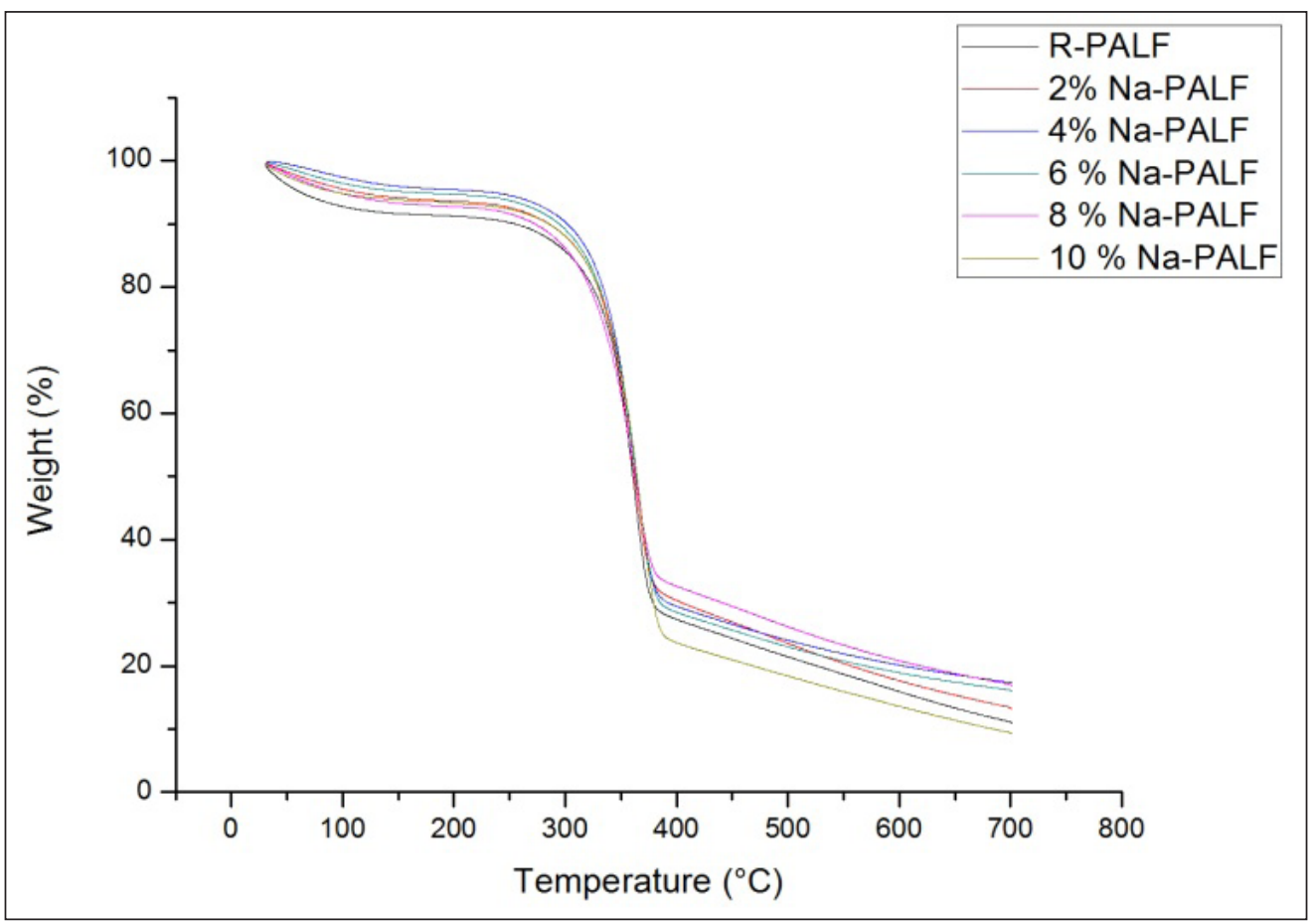

Fig. 6: TGA curves of untreated and alkali treated pineapple leaf fibers 


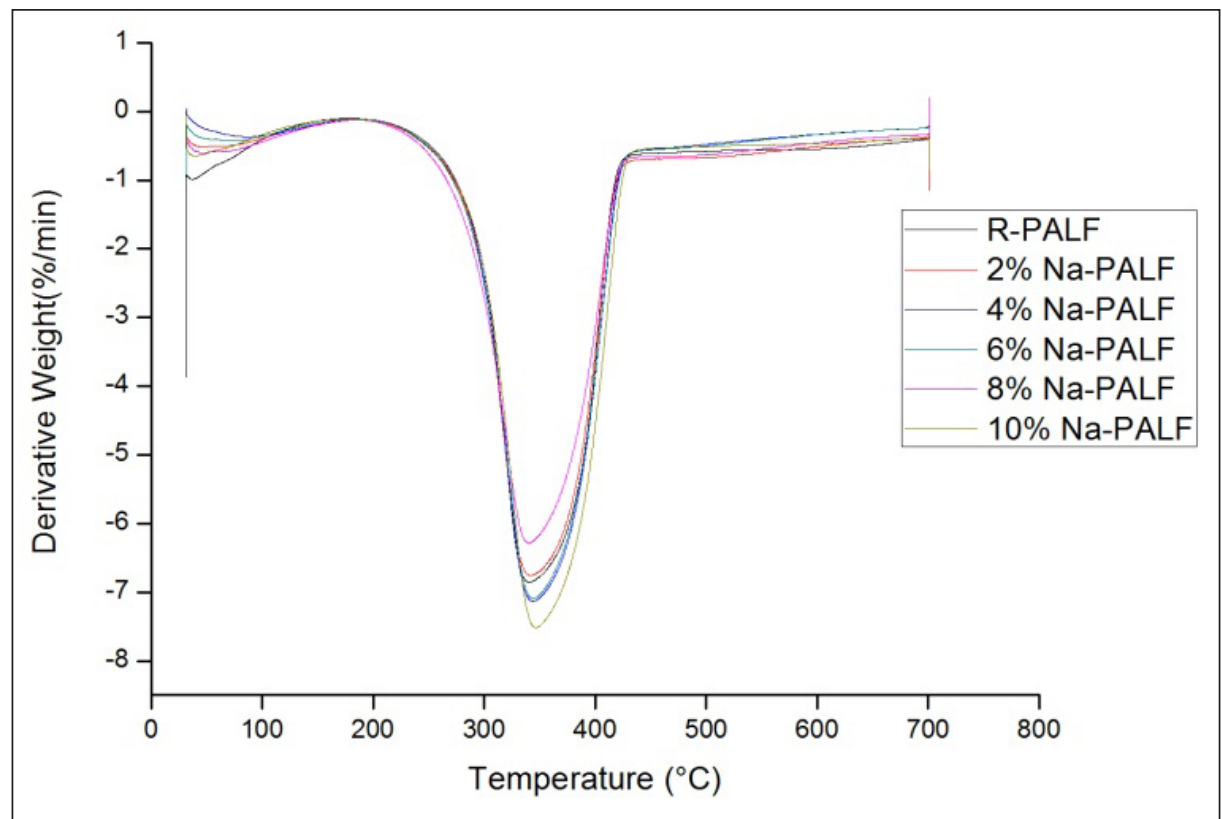

Fig. 7: DTG curves of untreated and alkali treated pineapple leaf fibers

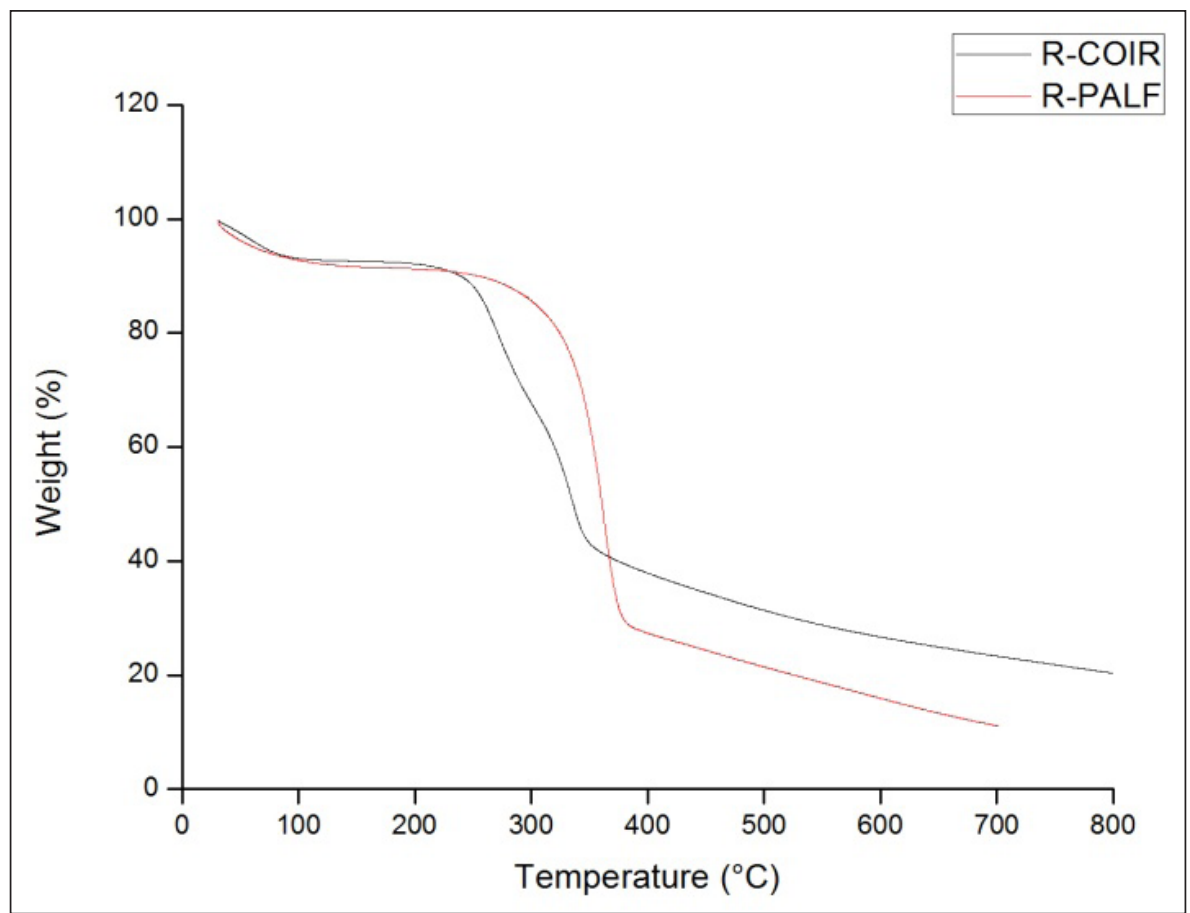

Fig. 8: TGA curve of untreated coir and pineapple leaf fiber 


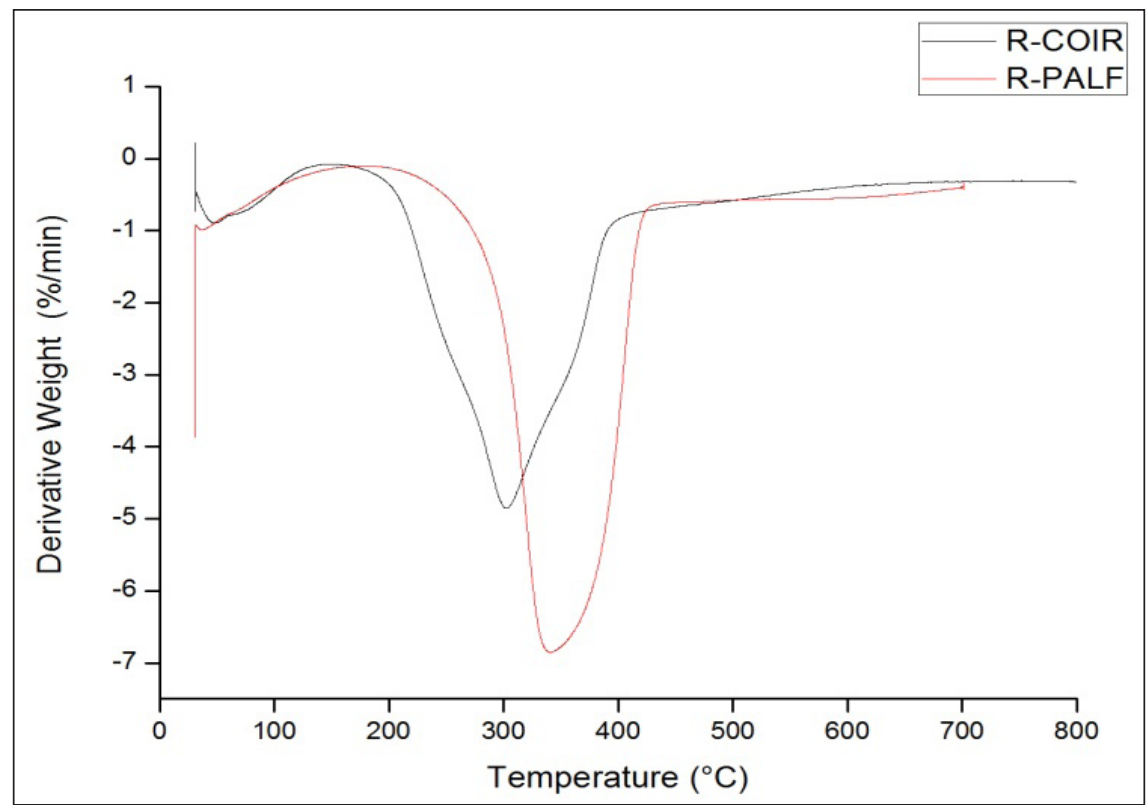

Fig. 9: DTG curve for untreated coir and pineapple leaf fiber

Table 4 and 5 depicts that the weight loss in all cases (Untreated and $\mathrm{NaOH}$ treated PALF and COIR fibers) is negligible below $290^{\circ} \mathrm{C}$; major mass loss (30-50 wt \%) occur above this temperature and it was due to the degradation of crystalline cellulose. M. Siti. Alwani et al. ${ }^{[37]}$ also reported that the major mass loss (30-50\%) in SCB, PALF, COIR, and BPS fibers occurred at a temperature above than $300^{\circ} \mathrm{C}$. Hemicellulose decomposition is the first stage of fiber degradation. As the temperature increases, the cellular breakdown of hemicellulose takes place. The coconut husk fibers started to decompose at $150^{\circ} \mathrm{C}$; however, the pineapple leaf fibers decompose at $185^{\circ} \mathrm{C}$. In both cases, the peak temperature of maximum degradation was shifted to a higher temperature after an alkaline treatment. The $4 \mathrm{wt} \% \mathrm{NaOH}$ treated COIR fiber exhibits higher peak temperature of thermal degradation (about $20^{\circ} \mathrm{C}$ ) than that of untreated one. This was due to the removal of hemicellulose after an alkaline treatment of cellulosic fibers. Yang et al. ${ }^{[38]}$ reported that the presence of a carbonyl group $(\mathrm{C}=\mathrm{O})$ in hemicellulose be the cause of its lower thermal stability than that of $\alpha$-cellulose, and lignin. Ndazi Bwire $\mathrm{S}$ et al. ${ }^{[19]}$ reported the reduction in a temperature of maximum weight loss after an alkaline treatment of rice husk fiber and it was due to the excess removal of cementing materials like hemicellulose and lignin. The main degradation peak lies within $290^{\circ} \mathrm{C}-380^{\circ} \mathrm{C}$ temperature with $50 \%$ degradation. The PALF possess higher mass loss (around $10 \%$ ) as compared to COIR fiber. This was because of the high cellulose content in PALF. However, the degradation of PALF occurs at a higher temperature than that of COIR fiber. M. Siti. Alwani et al. ${ }^{[3]}$ reported that the sugarcane bagasse fiber exhibits higher mass loss than that of pineapple leaf, banana, and coconut fibers. This was attributed to the presence of high cellulose content in SCB fiber.

Lignin was the most thermally stable component of a cellulosic fiber due to its highly cross-linked complex aromatic structure. Mackay and Nassar ${ }^{[39]}$ reported that the thermal stability of lignocellulosic fibers is in the order: lignin $>\alpha$-cellulose $>$ hemicellulose. Lignin starts to decompose at a lower temperature (typically $\left.160-175^{\circ} \mathrm{C}\right)$ as compared to cellulose but it decomposes slowly under the whole temperature range and its 
temperature extends as high as $900^{\circ} \mathrm{C}$. According to Paiva et al. ${ }^{[40]}$, the decomposition of lignin occurred in a wider temperature range as compared to the cellulose and hemicellulose components. Table 4 and 5 clearly revealed that the remaining mass of COIR was higher than PALF fiber after $700^{\circ} \mathrm{C}$. This was attributed to the presence of a large amount of lignin compound in COIR fiber. Williams et al. ${ }^{[41]}$ reported that the high lignin content in lignocellulosic fibers leads to a high amount of residues during pyrolysis. It was observed that the $4 \mathrm{wt} \% \mathrm{NaOH}$ treated COIR and PALF fibers possess higher residual mass than that of untreated fibers. This was due to the slow rate of chemical decomposition reaction and dominance of the formation of condensed cellulose as the solid residue.

Table 6 and 7 illustrate the DTG results of untreated and alkali treated fibers. In case of untreated COIR fiber, the two decomposition peaks at $228^{\circ} \mathrm{C}$ and $302^{\circ} \mathrm{C}$ at the rate of 1.475 and $4.852 \% / \mathrm{min}$ correspond to the decomposition of hemicellulose and cellulose components. It was observed that the rate of hemicellulose decomposition is more prominent in untreated fibers (PALF and COIR) as compared to alkali treated fibers. Pineapple leaf fiber exhibits a higher rate of decomposition than coconut husk fiber. Thus from DTG results, we can conclude that the alkaline treated fibers possess degradation peak at a higher temperature than that of untreated fibers.

Table 4: TGA of untreated and treated coir fibers

\begin{tabular}{|c|c|c|c|}
\hline Fiber & Temperature Range ${ }^{\circ} \mathrm{C}$ & Weight Loss (\%) & Residual mass $(\%)$ at $\left(700^{\circ} \mathrm{C}\right)$ \\
\hline \multirow{3}{*}{ R-COIR } & $0-152.4$ & 7.396 & \multirow{3}{*}{23.359} \\
\hline & $152.4-242.85$ & 3.05 & \\
\hline & $242.85-352.94$ & 46.49 & \\
\hline \multirow{3}{*}{$2 \% \mathrm{Na}-\mathrm{COIR}$} & $0-161.9$ & 7.4 & \multirow{3}{*}{22.94} \\
\hline & $161.9-262.01$ & 3.68 & \\
\hline & $262.01-361.86$ & 42.73 & \\
\hline \multirow{3}{*}{$4 \% \mathrm{Na}-\mathrm{COIR}$} & $0-176.06$ & 8.07 & \multirow{3}{*}{25.135} \\
\hline & $176.06-277.08$ & 5.7 & \\
\hline & $277.08-363.15$ & 39.39 & \\
\hline \multirow{3}{*}{$6 \% \mathrm{Na}-\mathrm{COIR}$} & $0-176.19$ & 7.66 & \multirow{3}{*}{23.409} \\
\hline & $176.19-271.44$ & 4.8 & \\
\hline & $271.44-376.18$ & 47.29 & \\
\hline \multirow{3}{*}{$8 \% \mathrm{Na}-\mathrm{COIR}$} & $0-152.38$ & 6.65 & \multirow{3}{*}{24.64} \\
\hline & $152.38-266.72$ & 4.7 & \\
\hline & $266.47-376.25$ & 43.43 & \\
\hline \multirow{3}{*}{$10 \% \mathrm{Na}-\mathrm{COIR}$} & $0-171.52$ & 7.55 & \multirow{3}{*}{25.15} \\
\hline & $171.52-276.12$ & 5.69 & \\
\hline & $276.12-361.95$ & 40.92 & \\
\hline
\end{tabular}


Table 5: TGA of untreated and treated pineapple leaf fibers

\begin{tabular}{cccc}
\hline Fiber & Temperature Range ${ }^{\mathbf{0}} \mathbf{C}$ & Weight Loss (\%) & Residual Char (\%) \\
\hline \multirow{2}{*}{ R-PALF } & $0-184.78$ & 8.63 & 11.103 \\
& $184.78-330.4$ & 13.63 & \\
& $330.4-382.66$ & 48.75 & 13.356 \\
2\% Na-PALF & $0-164.31$ & 6.071 & \\
& $164.31-261.85$ & 1.97 & 17.34 \\
4\% Na-PALF & $261.85-361.97$ & 41.98 & \\
& $0-184.04$ & 4.465 & 16.14 \\
6\% Na-PALF & $184.04-324.15$ & 11.18 & \\
& $324.15-376.7$ & 49.59 & 17.01 \\
& $0-175.1$ & 5.12 & \\
8\% Na-PALF & $175.1-321.7$ & 11.16 & \\
& $321.7-378.32$ & 50.57 & \\
& $0-186.88$ & 7.162 & \\
& $186.88-315.15$ & 10.54 & \\
\hline 0 Na-PALF & $315.15-378.23$ & 46.56 & \\
& $0-186.95$ & 6.545 & 12.03 \\
\hline
\end{tabular}

Table 6: DTG of untreated and treated coir fibers

\begin{tabular}{|c|c|c|}
\hline Fiber & Temperature ${ }^{0} \mathrm{C}$ & Rate of Weight Loss $(\% / \mathrm{min})$ \\
\hline \multirow{3}{*}{ R-COIR } & 48.43 & 0.897 \\
\hline & 228.43 & 1.475 \\
\hline & 302.56 & 4.852 \\
\hline \multirow{3}{*}{$2 \% \mathrm{Na}-\mathrm{COIR}$} & 72.47 & 0.697 \\
\hline & 243.35 & 1.162 \\
\hline & 314.3 & 4.774 \\
\hline \multirow{3}{*}{$4 \% \mathrm{Na}-\mathrm{COIR}$} & 73.61 & 0.67 \\
\hline & 250.13 & 1.156 \\
\hline & 321.74 & 4.708 \\
\hline \multirow{3}{*}{$6 \% \mathrm{Na}-\mathrm{COIR}$} & 74.43 & 0.428 \\
\hline & 252.74 & 0.565 \\
\hline & 325.9 & 5.061 \\
\hline \multirow{3}{*}{$8 \% \mathrm{Na}-\mathrm{COIR}$} & 90.80 & 0.571 \\
\hline & 252.96 & 1.413 \\
\hline & 321.09 & 4.62 \\
\hline \multirow{3}{*}{$10 \% \mathrm{Na}-\mathrm{COIR}$} & 72.77 & 0.693 \\
\hline & 258.48 & 1.719 \\
\hline & 321.95 & 4.894 \\
\hline
\end{tabular}


Table 7: DTG of untreated and treated pineapple leaf fibers

\begin{tabular}{|c|c|c|}
\hline Fiber & Temperature ${ }^{\circ} \mathrm{C}$ & Rate of Weight Loss (\%/min) \\
\hline \multirow{4}{*}{ R-PALF } & 31.16 & 1.47 \\
\hline & 310.82 & 3.54 \\
\hline & 341.58 & 6.85 \\
\hline & 46.37 & 0.52 \\
\hline \multirow[b]{2}{*}{$2 \% \mathrm{Na}-\mathrm{PALF}$} & 247.81 & 0.49 \\
\hline & 341.52 & 6.75 \\
\hline \multirow{4}{*}{$4 \% \mathrm{Na}-\mathrm{PALF}$} & 85.79 & 0.37 \\
\hline & 308.69 & 3.39 \\
\hline & 343.43 & 7.13 \\
\hline & 70.83 & 0.43 \\
\hline \multirow[b]{2}{*}{$6 \% \mathrm{Na}-\mathrm{PALF}$} & 302.33 & 2.73 \\
\hline & 343.12 & 7.091 \\
\hline \multirow{4}{*}{$8 \% \mathrm{Na}-\mathrm{PALF}$} & 46.49 & 0.60 \\
\hline & 300.08 & 2.71 \\
\hline & 339.72 & 6.28 \\
\hline & 39.7 & 0.65 \\
\hline \multirow[b]{2}{*}{$10 \% \mathrm{Na}-\mathrm{PALF}$} & 313.05 & 3.66 \\
\hline & 346.85 & 7.51 \\
\hline
\end{tabular}

\section{CONCLUSION}

In this work, an experimental investigation was carried out to study the thermal behavior of untreated and alkali treated PALF and COIR fibers. From this study, the following conclusions can be made:

$\square$ The thermal decomposition of PALF and COIR fibers proceeded in two steps. In $1^{\text {st }}$ step, a minor weight loss occurs due to an evaporation of water and extraction of volatile compounds and in the $2^{\text {nd }}$ step, major degradation occurs due to the decomposition of hemicellulose, cellulose, and lignin components.

$\square$ The alkaline treatment of PALF and COIR fibers leads to a lower weight loss and shifting of degradation peak to a higher temperature.

$\square$ Amongst all the samples, the $4 \mathrm{wt} \% \mathrm{NaOH}$ treated PALF and COIR fibers exhibit maximum thermal stability. This improvement was due to the removal of less thermally stable hemicellulose component after an alkaline treatment. The temperature of maximum decomposition was shifted from $302^{\circ} \mathrm{C}$ to $321^{\circ} \mathrm{C}$ after the $4 \mathrm{wt} \%$ alkaline treatment of COIR fiber.

$\square$ Pineapple leaf fiber exhibits a higher rate of decomposition $(6.85 \% / \mathrm{min})$ than coir fiber $(4.85 \% /$ min). It was due to the presence of more cellulosic content in PALF.

$\square$ After $700^{\circ} \mathrm{C}$, the remaining mass of COIR (23.35\%) was higher as compared to PALF (11.10\%). This might be attributed to the presence of high lignin content in COIR fiber. 


\section{ACKNOWLEDGMENTS}

The authors gratefully acknowledge all support received from Analytical Instrument Laboratory at CSIR-CSIO, Chandigarh.

Conflicts of Interest: The authors declare no conflict of interest.

Funding: This research work received no specific grant from any funding agency in the public, commercial, and nonprofit sectors.

\section{REFERENCES}

1. Maguno, A. 1999. $2^{\text {nd }}$ International wood and natural fiber composites symposium, Kassel, Germany.

2. Qureshi, H.A. 1999. $2^{\text {nd }}$ International wood and natural fiber composites symposium, Kassel, Germany.

3. Nickel, J. and Riedel, U. 2003. Activities in biocomposites. Materials Today, pp. 44-48.

4. Anuar, H., Ahmad, S., Rasid, R., Ahmad, A., and Busu, W. 2008. Mechanical properties and dynamic mechanical analysis of thermoplastic natural rubber reinforced short carbon fiber and kenaf fiber hybrid composites. J. Appl. Polym. Sci., 107(6): 4043-4052.

5. Barreto, A., Esmeraldo, M., Rosa, D., Fechine, P. and Mazzeto, S. 2010. Cardanol biocomposites reinforced with jute fiber: microstructure, biodegradability, and mechanical properties. Polym. Compos. 31(11): 1928-1937.

6. Mohanty, A.K., Misra, M. and Drzal, L.T. 2005. Natural fibers, biopolymers and biocomposites. Boca Raton: CRC Press.

7. Asim, M., Abdan, K., Jawaid, M., Nasir, M., Dashtizadeh, Z., Ishak, M.R. and Hoque, M. 2015. A review on pineapple leaves fibre and its composites, Int. J. Polym. Sci. http://dx.doi.org/10.1155/2015/950567.

8. Mittal, M. and Chaudhary, R. 2018. Experimental study on the water absorption and surface characteristics of alkali treated pineapple leaf fiber and coconut husk fiber. Int. J. Appl. Eng. Res., 13(15): 12237-12243.

9. Mittal, M. and Chaudhary, R.2018. Experimental investigation on the mechanical properties and water absorption behavior of randomly oriented short pineapple/coir fiber-reinforced hybrid epoxy composites, Mater. Res. Express.

10. Mittal, M. and Chaudhary, R. 2018. Effect of fiber content on thermal behavior and viscoelastic properties of PALF/Epoxy and COIR/Epoxy composites, Mater. Res. Express.

11. Statistical databases of "Food and Agriculture Organization of the United Nations", www.fao.org/ statistics/databases/en/.

12. Mwaikambo, L.Y. and Ansell, M.P. 2002. Chemical modification of hemp, sisal, jute, and kapok fibers by alkalization. J. Appl. Polym. Sci., 84: 2222-2234.

13. John, M.J., Francis, B., Varughese, K.T. and Thomas, S. 2008. Effect of chemical modification on properties of hybrid fiber biocomposites. Comp. Part A., 39: 352-363. 
14. Li, X., Tabil, L.G. and Panigrahi, S. 2007. Chemical treatments of natural fiber for use in natural fiberreinforced composites: A Review. J. Polym. Environ., 15: 25-33.

15. John, M.J. and Anandjiwala, R.D. 2008. Recent developments in chemical modification and characterization of natural fiber reinforced composites. Polym. Comp., pp187-207.

16. Slopiecka, K., Bartocci, P. and Fantozzi, F. 2012. Thermogravimetric analysis and kinetic study of poplar wood pyrolysis. Appl. Energy, 97: 491-497.

17. Oushabi, A., Sair, S., Oudrhiri Hassani, F., Abboud, F., Tanane, O. and Bouari, A. 2017. The effect of alkali treatment on mechanical, morphological, and thermal properties of date palm fibers: Study of the interface of DPF-Polyurethane composite. Sou. Afr. J. Chem. Eng., 23: 116-123.

18. Panyasart, K., Chaiyut, N., Taweechai, A. and Onuma, S. 2014. Effect of surface treatment on the properties of pineapple leaf fibers reinforced polyamide 6 composites. $11^{\text {th }}$ Eco-Energy and Materials Science and Engineering, 56: 406-413.

19. Ndazi, B.S., Christian, N. and Joseph, T. 2007. Chemical and thermal stability of rice husks against alkali treatment. Bioresources, 3(4): 1267-1277.

20. Rachini, A., Troedec, M.L., Peyratout, C. and Smith, A. 2009. Comparison of the thermal degradation of natural, alkali treated, and silane treated hemp fibers under air and an inert atmosphere. J. Appl. Polym. Sci., 112: 226-234.

21. Mortari, D.A., Britto, M.C. and Crnkovic, P.M. Correlation between activation energy and thermal decomposition yield of sugar cane bagasse under $\mathrm{CO}_{2} / \mathrm{O}_{2}$ and $\mathrm{N}_{2} / \mathrm{O}_{2}$. Chem. Eng. Trans., 37: 31-36.

22. White, J.E., Catallo, W.J. and Legendre, B.L. 2011. Biomass pyrolysis kinetics: A comparative critical review with relevant agricultural residue case studies. J. Anal. Appl. Pyrol., 91(1): 1-33.

23. Yao, F., Wu, Q., Lei, Y., Guo, W. and Xu, Y. 2008. Thermal decomposition kinetics of natural fibers: Activation energy with dynamic thermogravimetric analysis. Polym. Degr. Stab., 93: 90-98.

24. Sergio, N.M., Veronica, C. and Rodriguez, R.J.S. 2012. The thermogravimetric behavior of natural fibers reinforced polymer composites, Mater. Sci. Eng., 557: 17-28.

25. Rachini, A., Troedec, M.L., Peyratout, C. and Smith, A. 2009. Comparison of the thermal degradation of natural, alkali treated, and silane treated hemp fibers under air and an inert atmosphere. J. Appl. Polym. Sci., 112: 226-234.

26. Tajvidi, M. and Takemura, A. 2010. Thermal degradation of natural fiber reinforced polypropylene composites, J. Thermoplast. Compos. Mater., 23: 281-298.

27. Na Lu and Oza, S. 2013. Effect of surface treatment of hemp fibers on the thermal stability of Hemp-PLA composites. Adv. Mat. Res., 651: 499-504.

28. Jayamani, E., Hamdan, S., Rahman, Md., Khusairy, M. and Bakri, B. 2014. Investigation of fiber surface treatment on mechanical, acoustical, and thermal properties of betel nut fiber polyester composites. $12^{\text {th }}$ Global Congress on Manufacturing and Management, 97: 545-554. 
29. Mittal, M. and Chaudhary, R. 2018. Development of PALF/Glass and COIR/Glass fiber reinforced hybrid epoxy composites, J. Mat. Sci. Surf. Eng., 6(5): 851-861.

30. Ranjan, R., Bajpai, P.K. and Tyagi, R.K. 2013. Mechanical characterization of Banana/Sisal fiber reinforced PLA hybrid composites for structural applications, Eng. Int., 1(1): 39-49.

31. Devi, L.U., Bhagawan, S.S., Nair, K.C.M. and Thomas, S. 2011. Water absorption behavior of PALF/GF hybrid polyester composites, Polym. Compo., doi: 10.1002/pc.21034.

32. Goud, G. and Rao, R.N. 2010. Effect of fiber content and alkali treatment on mechanical properties of Roystonea regia-reinforced epoxy partially biodegradable composites, B. Mater. Sci., 34(7): 1575-1581.

33. Anand, P. and Anbumalar, V. Mechanical properties of cellulose-filled epoxy hybrid composites reinforced with alkali-treated hemp fiber, Polym., 39(1): 46-55.

34. Venkateshappa, S.C., Jayadevappa, S.Y. and Puttiah, P.K.W. 2011. Mechanical behavior of areca fiber reinforced epoxy composites, Adv. Polym. Technol., 31(4): 319-330.

35. Ndazi, B., Tesha, J. and Bisanda, E. 2006. Some opportunities and challenges of producing bio-composites from non-wood residues. J. Mat. Sci., 41(21): 6984-6990.

36. Arifuzzaman Khan, G.M. and Shamsul Alam Md. 2012. Thermal characterization of chemically treated coconut husk fibre. Ind. J. Fib. Tex. Res., 37: 20-26.

37. Alwani, M.S., Khalil, H.P.S., Sulaiman, O., Islam Md, and Dungani, R. 2014. An approach to using agricultural waste fibres in biocomposite application: Thermogravimetric analysis and activation energy study. Bioresources., 9: 218-230.

38. Yang, H., Yan, R., Chen, H., Lee, D.H. and Zheng, C. 2007. Characteristics of hemicellulose, cellulose, and lignin pyrolysis. Fuel., 86(12):1781-1788.

39. Nasar, M.N. and MacKay, G.D.M. 1984. Mechanism of thermal decomposition of lignin. Wood. Fib. Sci., 16(3): 441-453.

40. Paiva, J.M. and Frollini, E. 2006. Unmodified and modifies surface sisal fibers as reinforcement of phenolic and lignophenolic matrices composites: Thermal analysis of fibers and composites. Macromol. Mater. Eng., 291: 405-417.

41. Williams, P.T. and Reed, A.R. 2004. Thermal processing of biomass natural fibre wastes by pyrolysis. Int. J. Energy. Res., 28(2): 131-145. 